\title{
Association between sociodemographic factors and nutritive and non-nutritive sucking habits among Iranian girls
}

A. Jahanbin, ${ }^{7}$ N. Mokhber ${ }^{7}$ and A. Jabbarimani ${ }^{7}$

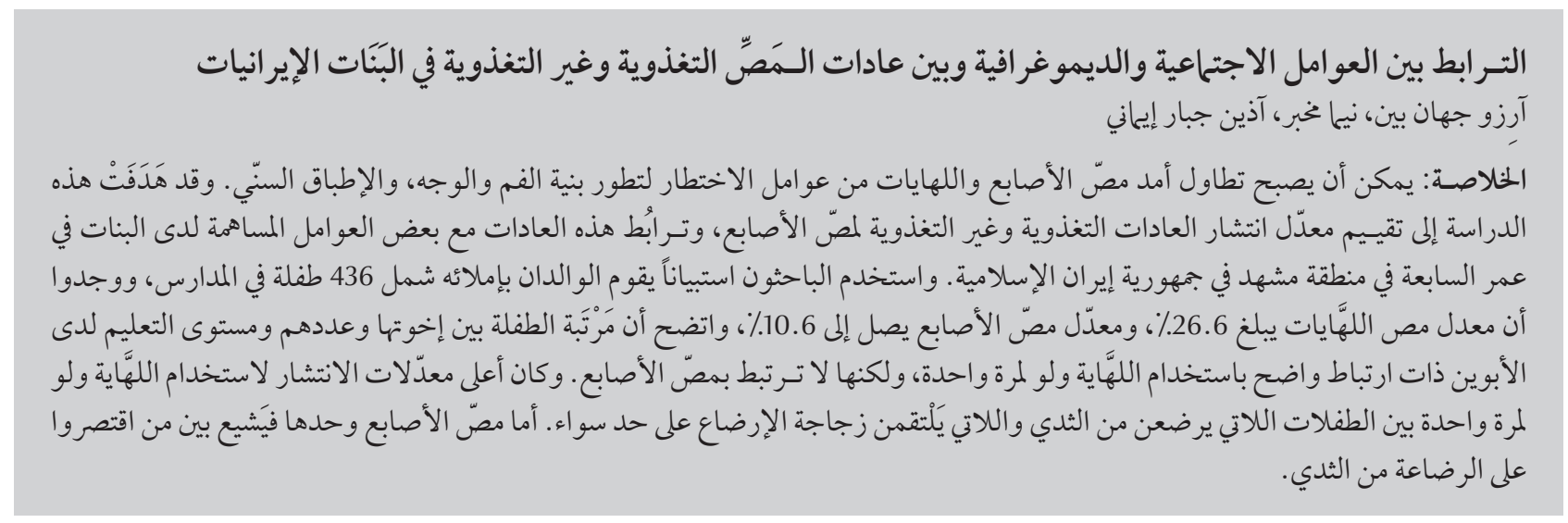

ABSTRACT Prolonged duration of finger- and pacifier-sucking may be a risk factor for maldevelopment of orofacial structures and dental occlusion. This study assessed the prevalence of nutritive and non-nutritive sucking habits and their association with some contributing factors among 7-year-old girls in Mashhad, Islamic Republic of Iran. Based on a questionnaire to the parents of 436 schoolgirls, the rate of current or previous pacifier-sucking was $26.6 \%$ and of finger-sucking was $10.6 \%$. Child's birth rank and number of siblings and parents' educational level were significantly related to ever pacifier-sucking but not to finger-sucking. The highest prevalence of ever pacifier-sucking was among children who had been breast- and bottle-fed but finger-sucking was more common among exclusively breastfed children.

Association entre les facteurs démographiques et les habitudes de succion nutritive et non nutritive chez les fillettes iraniennes

RÉSUMÉ La succion du pouce - et de la tétine - pendant une période prolongée peut représenter un facteur de risque pour le mauvais développement des structures orofaciales et l'occlusion dentaire. Cette étude portait sur la prévalence des habitudes de succion nutritive et non nutritive et leur association avec certains facteurs qui y contribuent chez les filles de 7 ans à Mashhad (République islamique d'Iran). D'après un questionnaire soumis aux parents de 436 filles, le taux de succion de la tétine au moment de l'étude ou auparavant était de 26,6 \% et celui de succion du pouce était de 10,6 \%. Le rang de naissance de l'enfant, le nombre de frères et soeurs et le niveau d'instruction des parents étaient significativement liés à la succion de la tétine au moins une fois mais pas à la succion du pouce. La plus forte prévalence de succion de la tétine à un moment donné de leur existence se trouvait chez les enfants qui avaient reçu une alimentation mixte sein et biberon mais la succion du pouce était plus courante chez les enfants nourris exclusivement au sein. 


\section{Introduction}

Although non-nutritive sucking behaviours in infants may be a sign of psychological and physiological needs for nutrition [1], it may be a risk factor for maldevelopment of orofacial structures and dental occlusion. Prolonged finger-sucking has been associated with a higher incidence of anterior open bite, maxillary incisor protrusion, class II canine relationship, distal-step molar relationship, posterior crossbites, lip incompetence, increased tongue thrust and speech defects [2]. Similarly, although pacifier (dummy) use has been suggested to reduce the risk of sudden infant death syndrome, it can cause accidents, breastfeeding failure, anterior open bite, class II molar relationships and recurrent acute otitis media. The development of latex allergy, tooth decay, oral ulcers and sleep disorders are other problems encountered with pacifier use [3-5]. In contrast, Bishara et al. showed that children who have pacifier- or finger-sucking habits lasting less than 12 months did not have significantly different occlusal characteristics than children who were breast-fed for 6 to 12 months [6].

Several authors believe that the method of feeding has no appreciable influence on the acquisition of nonnutritive sucking habits in infants, while others have suggested that there is a reduced prevalence of these habits among breastfeeders [7-18]. In contrast, Paunio et al. reported a greater risk of finger-sucking [19] and Vadiakas et al. found higher rates of pacifier-sucking and lower rates of finger-sucking [10] among children who had been breastfed for a long time.

There is convincing evidence that some factors, such as the educational level of parents, the child's birth rank and number of siblings, have an influence on finger- and pacifier-sucking habits $[9,20]$. It has been claimed that children of higher socioeconomic status demonstrated finger-sucking more frequently than children of lower socioeconomic status, whereas dummysucking was more prevalent in the lower socioeconomic groups [21]. According to Warren et al. older maternal age and higher maternal education level and having no older siblings were the most important factors in children developing prolonged non-nutritive sucking habits [1].

The aims of the present study were to determine the prevalence of nutritive and non-nutritive sucking habits and the association of sucking habits with some socioeconomic factors in an Iranian sample.

\section{Methods}

This cross-sectional study was conducted using a survey questionnaire. A sample of 436 7-year-old girls were selected from schools in Mashhad, Islamic Republic of Iran using a stratified cluster randomized sampling technique. The schools were stratified by housing density and housing/living conditions of each school district. Nine schools were selected randomly and random number tables were used to select the girls within the schools.

The questionnaires were delivered to parents by the pupils with a covering letter requesting that the forms be completed by the mother (with the assistance of a literate family member if necessary). The questionnaire included questions about the mother's and father's educational level and the child's birth rank, number of siblings, history and duration of breast- or bottle-feeding during the first 2 years of life and the children's previous or current nonnutritive sucking habits.

The results from the questionnaires were carefully reviewed by the authors and if 1 or more questions had not been answered, or one of the parents was deceased or divorced, the questionnaires were excluded and replacement students were selected from the same schools.

The data were analysed using SPSS, version 10 software, and chi-squared tests to analyse the effect of contributing factors on the prevalence of sucking habits.

\section{Results}

Of the 436 girls, $116(26.6 \%)$ had a previous or current pacifier-sucking habit while $46(10.6 \%)$ had a previous or current finger-sucking habit. The children's history of non-nutritive sucking showed that pacifier-sucking was mostly practised during the first 2 years of life (by $81.9 \%$ of pacifier-suckers) and very few were still using a pacifier after 4 years of age $(0.9 \%)$. Among finger-suckers the rates were $37.3 \%$ practising the habit for $<2$ years, $29.4 \%$ for $2-4$ years and $33.3 \%$ for $>4$ years respectively (Figure 1).

Girls whose birth rank was 4th or more were significantly less likely to have a pacifier-sucking habit (7.8\%) than those who were the 1st child (45.7\%) and 2nd or 3rd child (46.6\%) $(P=0.012)$, but the rate of finger-sucking not significantly associated with a child's birth rank (17.4\% for birth rank 4 th,$+ 41.3 \%$ for rank 1 st or $2 \mathrm{nd}$ and $41.3 \%$ for 3 rd rank $)(P=0.780)$.

The number of siblings in the family played a strong role. The rate of pacifier-sucking was $8.6 \%$ for girls with $5+$ siblings compared with $38.8 \%$ with 3 or 4 siblings and $52.6 \%$ with 1 or 2 siblings $(P=0.005)$. However, there was no significant association between finger-sucking and number of siblings $(P=0.928)$.

The rates of non-nutritive sucking tended to increase with increasing educational level of parents, although this was only significant for pacifier-sucking not for finger-sucking (Table 1).

A total of $65.4 \%$ of the girls had been exclusively breastfed, $27.3 \%$ breast- and 
bottle-fed and $7.3 \%$ exclusively bottlefed in the first 2 years of their life (Table 1). The prevalence of pacifiersucking was significantly higher among girls who had been exclusively breastfed $(39.7 \%)$ or breast- and bottle-fed (46.6\%) than children who were exclusively bottle-fed (13.8\%) The rates of finger-sucking, however, were not significantly affected by the type of feeding in the first 2 years of life; the corresponding figures were $65.2 \% 13.0 \%$ and $21.7 \%$ respectively.

\section{Discussion}

The main aims of this cross-sectional study were to evaluate the prevalence of previous or persisting finger- and pacifier-sucking habits and determine the association between these habits and some contributing factors among 7-year-old girls in Mashhad.

This study showed that the prevalence of current or previous pacifier and finger-sucking habits were $26.6 \%$ and $10.6 \%$ respectively. The prevalence of pacifier-sucking in our study was lower than that reported by some investigators: $40 \%, 37 \%$ and $40 \%$ in the United States of America, Norway and Saudi Arabia respectively $[6,13,14]$. These differences in the total prevalence of pacifier-sucking habits among different cultures warrant further investigation of the etiology of the habit. In contrast, the prevalence of finger-sucking was very similar to other studies: $12 \%, 10 \%$ and $11 \%$ in Norway, Sweden and Saudi Arabia respectively $[13,22,23]$. These findings suggest that the etiology of finger-sucking remains the same in different populations and cultures.

Our study demonstrated that a majority of children were pacifier-sucking in the first 2 years of life (81.9\%), but fewer $(17.2 \%)$ between ages $2-4$ years, while only $0.9 \%$ practised the habit after 4 years of age. Similarly, Bishara et al. showed that pacifier-sucking decreased

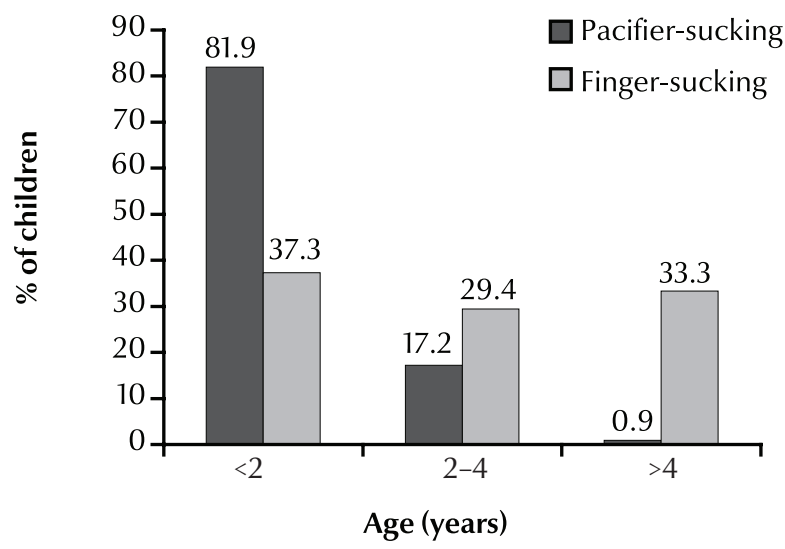

Figure 1 Mothers' reports of the child's history of ever finger- and pacifier-sucking by age among 7-year-old girls in Masshad ( $n=46$ for finger-sucking; $n=116$ for pacifier-sucking)

from $20 \%$ for 1-2-year-olds to almost zero after age 5 years [6]. Although the pacifier-sucking habit was more prevalent in the first 2 years of life, the prevalence of finger-sucking changed less with age, remaining around onethird of girls. Bishara et al. found that the prevalence of pacifier-sucking decreased between 3-8 years of age from $10 \%$ to $0.3 \%$, whereas that of fingersucking decreased from $14 \%$ to $4 \%$ [6]. Duncan et al. also reported that at 15 months of age, $63.2 \%$ of children had a reported non-nutritive sucking habit that reduced to $40 \%$ by the age of 36 months [5].

The distribution of sucking habits according to parent's education showed that the higher the level of parent's education, the higher the probability that the child was a pacifier-sucker, except for parents with college level education whose children had a lower prevalence of sucking habits. These observations are similar to Farsi and Salama who found dummy-sucking to be more prevalent among the children of parents of higher educational levels [14]. Aarts et al. found that maternal age and education only slightly modified the association between pacifier use and breastfeeding duration [24]. It is unclear why less educated parents were less likely than others to have children with a pacifier-sucking habit; however it could be due to the greater time that educated mothers spend working outside the home. On the other hand, the prevalence of finger-sucking did not show a significant association with the level of parent's education. This finding is in agreement with Farsi and Salama [14] and in contrast to Wolf and Lozoffs study [25].

Our study showed a significant relationship between birth rank and prevalence of pacifier-sucking. We demonstrated that children with 4 or more siblings were less likely to have a pacifiersucking habit. It has been suggested that a family with 4 children represents the optimum number from a psychological perspective [26]. These results agree with Bayardo et al,, who showed that a single child was more likely to develop a sucking behaviour while children with 5 or more siblings were the least likely to do so [26].

The results of our study contradict reports that the method of feeding in infancy has no substantial influence on the acquisition of non-nutritive sucking habits $[8,9,11,15]$. Data about the role of breastfeeding in non-nutritive sucking habits is contradictory. Some authors assume that infants who are breastfed for a reasonably long period of time are less likely to become finger-suckers than babies who have no breastfeeding experience $[13,18,23]$. But the results of our 


\begin{tabular}{|c|c|c|c|c|c|c|c|}
\hline \multirow[t]{2}{*}{ Factor } & \multirow{2}{*}{$\begin{array}{l}\text { Total sample } \\
\qquad \begin{array}{c}(n=436) \\
\%\end{array}\end{array}$} & \multicolumn{3}{|c|}{$\begin{array}{l}\text { Finger-sucking } \\
\qquad(n=46)\end{array}$} & \multicolumn{3}{|c|}{$\begin{array}{l}\text { Pacifier-sucking } \\
\quad(n=116)\end{array}$} \\
\hline & & $\%$ & $x^{2}$-value & $P$-value & $\%$ & $\chi^{2}$-value & $P$-value \\
\hline Father's education & & & 2.1 & 0.717 & & 10.2 & 0.036 \\
\hline No formal education & 1.1 & 0.0 & & & 1.7 & & \\
\hline Primary school & 1.8 & 0.0 & & & 9.0 & & \\
\hline Guidance school $^{\mathrm{a}}$ & 35.4 & 37.0 & & & 25.0 & & \\
\hline High school & 39.8 & 37.0 & & & 50.0 & & \\
\hline College & 21.9 & 26.0 & & & 22.4 & & \\
\hline Mother's education & & & 1.2 & 0.875 & & 9.3 & 0.050 \\
\hline No formal education & 1.4 & 2.2 & & & 0.9 & & \\
\hline Primary school & 5.3 & 6.5 & & & 2.6 & & \\
\hline Guidance school & 34.9 & 30.4 & & & 26.7 & & \\
\hline High school & 42.6 & 47.8 & & & 52.6 & & \\
\hline College & 15.8 & 13.0 & & & 17.2 & & \\
\hline Birth rank & & & 0.50 & 0.870 & & 8.9 & 0.012 \\
\hline 1st child & 38.1 & 41.3 & & & 45.7 & & \\
\hline 2nd or 3rd child & 46.1 & 41.3 & & & 46.6 & & \\
\hline 4 th + child & 15.8 & 17.4 & & & 7.8 & & \\
\hline No. of siblings & & & 0.15 & 0.928 & & 10.5 & 0.005 \\
\hline 1 or 2 & 43.6 & 41.3 & & & 52.6 & & \\
\hline 3 or 4 & 38.5 & 39.1 & & & 38.8 & & \\
\hline $5+$ & 17.9 & 19.6 & & & 8.6 & & \\
\hline Type offeeding in first 2 years of life & & & 2.8 & 0.245 & & 46.4 & $<0.0001$ \\
\hline Bottle & 7.3 & 13.0 & & & 13.8 & & \\
\hline Breast & 64.5 & 65.2 & & & 39.7 & & \\
\hline Bottle \& breast & 27.3 & 21.7 & & & 46.6 & & \\
\hline
\end{tabular}

study disagreed with this hypothesis, as the prevalence of finger-sucking was not significantly different among children who were exclusively breastfed, exclusively bottle-fed or both breast- and bottle-fed. In contrast, the prevalence of pacifier-sucking was significantly higher among children who had been breastand bottle-fed than children who were exclusively bottle-fed. These results agree with Paunio et al. [19]. This could be because feeding a child with both bottle and breast causes greater frustration to the child than experiencing no breastfeeding at all. Similarly, Aarts showed more frequent use of a pacifier is associated with shorter breastfeeding duration, even among mothers who were highly motivated to breastfeed [24]. Howard et al. suggested that the decreases in breastfeeding duration associated with pacifier use may be a consequence of less frequent breastfeeding among women who introduce pacifiers to their infants [27].

\section{Conclusions}

From the data collected in this study, the following conclusions may be drawn. Parents' educational level was positively related to pacifier-sucking habits with no substantial effect on finger-sucking. Child's birth rank and number of siblings had a significant effect on prevalence of pacifier-sucking habits but no significant effect on finger-sucking. The highest prevalence of pacifier-sucking habit was among children who were breast- and bottle-fed and the finger-sucking habit tended to be among exclusively breastfed children.

\section{Acknowledgements}

We would like to thank Dr Hadi Jabbari, Medical Statistician, for his assistance in the statistical analysis in this study.

This study was supported by the Dental Research Centre of the Mashhad University of Medical Sciences. 


\section{References}

1. Warren JJ et al. Non-nutritive sucking behaviors in preschool children: a longitudinal study. Pediatric Dentistry, 2000, 22(3):187-191.

2. Bishara SE, ed. Textbook of orthodontics. Philadelphia, WB Saunders, 2002.

3. Cinar DN. The advantages and disadvantages of pacifier use. Contemporary Nurse, 2004, 17(1-2):109-112.

4. Warren JJ et al. Effects of non-nutritive sucking habits on occlusal characteristics in the mixed dentition. Pediatric Dentistry, 2005, 27(6):445-450.

5. Duncan $\mathrm{K}$ et al. Sucking habits in childhood and the effects on the primary dentition: findings of the Avon Longitudinal Study of Pregnancy and Childhood. International Journal of Paediatric Dentistry, 2008, 18(3):178-188.

6. Bishara SE et al. Changes in the prevalence of non-nutritive sucking patterns in the first 8 years of life. American Journal of Orthodontics and Dentofacial Orthopedics, 2006, 130(1):31-36.

7. Larsson EF, Dahlin KG. The prevalence and the etiology of the initial dummy- and finger-sucking habit. American Journal of Orthodontics, 1985, 87(5):432-435.

8. Zadik D, Stern N, Litner M. Thumb- and pacifier-sucking habits. American Journal of Orthodontics, 1977, 71(2):197-201.

9. Hanna JC. Breast feeding versus bottle feeding in relation to oral habits. Journal of Dentistry for Children, 1967, 34(4):243249.

10. Vadiakas G, Oulis C, Berdouses E. Profile of non-nutritive sucking habits in relation to nursing behavior in pre-school children. Journal of Clinical Pediatric Dentistry, 1998, 22(2):133-136.

11. Meyers A, Hertzberg J. Bottle-feeding and malocclusion: is there an association? American Journal of Orthodontics and Dentofacial Orthopedics, 1988, 93(2):149-152.

12. Da Costa OO, Orenuga OO. The digit-sucking habit and related factors: observations from a child dental health clinic in Nigeria. African Journal of Medicine and Medical Sciences, 2003, 32(2):167-171.

13. Larsson E, Ogaard B, Lindsten R. Dummy and finger sucking habits in young Swedish and Norwegian children. Scandinavian Journal of Dental Research, 1992, 100(5):292-295.

14. Farsi NM, Salama FS. Sucking habits in Saudi children: prevalence, contributing factors and effects on the primary dentition. Pediatric Dentistry, 1997, 19(1):28-33.
15. Finocchi LL. Breast feeding, bottle feeding and their impact on oral habits. A review of the literature. Dental Hygiene, 1982, 56(11):21-25.

16. Scavone $\mathrm{H} \mathrm{Jr}$ et al. Association between breastfeeding duration and non-nutritive sucking habits. Community Dental Health, 2008, 25(3):161-165.

17. Levy SM et al. Associations of pacifier use, digit sucking, and child care attendance with cessation of breastfeeding. Journal of Family Practice, 2002, 51(5):465.

18. Ngom Pl et al. Prevalence et facteurs associes aux habitudes de succion non nutritive. Etude transversale chez des enfants senegalais ages de $5 / 6$ ans [Prevalence and factors associated with non-nutritive sucking behavior. Cross sectional study among 5- to 6-year-old Senegalese children]. L'Orthodontie Francaise, 2008, 79(2):99-106.

19. Paunio P, Rautava P, Sillanpää M. The Finnish Family Competence Study: the effects of living conditions on sucking habits in 3-year-old Finnish children and the association between these habits and dental occlusion. Acta Odontologica Scandinavica, 1993, 51(1):23-29.

20. Nanda RS, Khan I, Anand R. Effect of oral habits on the occlusion in preschool children. ASDC Journal of Dentistry for Children, 1972, 39(6):449-452.

21. Calisti LJ, Cohen MM, Fales MH. Correlation between malocclusion, oral habits, and socio-economic level of preschool children. Journal of Dental Research, 1960, 39:450-454.

22. Melsen B, Stensgaard K, Pedersen J. Sucking habits and their influence on swallowing pattern and prevalence of malocclusion. European Journal of Orthodontics, 1979, 1(4):271-280.

23. Modéer T, Odenrick L, Lindner A. Sucking habits and their relation to posterior cross-bite in 4-year-old children. Scandinavian Journal of Dental Research, 1982, 90(4):323-328.

24. Aarts $C$ et al. Breastfeeding patterns in relation to thumb sucking and pacifier use. Pediatrics, 1999, 104(4):e50.

25. Wolf AW, Lozoff B. Object attachment, thumb sucking, and the passage to sleep. Journal of the American Academy of Child and Adolescent Psychiatry, 1989, 28(2):287-292.

26. Bayardo RE et al. Etiology of oral habits. ASDC Journal of Dentistry for Children, 1996, 63(5):350-353.

27. Howard CR et al. The effects of early pacifier use on breastfeeding duration. Pediatrics, 1999, 103(3):e33. 